cosanoic acid (C26:0) by cultured skin fibroblasts from patients with adrenoleukodystrophy (ALD) and adrenomyeloneuropathy (AMN). J. Biochem., 90: 1233 (1981).

37. Uda, M., Singh, I., and Kishimoto, Y.: Glutamate formation from lignoceric acid by rat brain preparation in the presence of pyridine nucleotide and cytosolic factors. Biochemistry, 20: 1295 (1981).

38. Ulrich, J., Herschkowitz, N., Heitz, P., Sigrist, T., and Baerlocher, P.: Adrenoleukodystrophy: preliminary report of a connatal case. Acta Neuropathol., 43: 77 (1978).

39. Versmold, H. T., Bremer, H. J., Herzog, V., Siegel, G., Bassewitz, D. B. V., Irle, U., Voss, H. V., Lombeck, I., and Brauser, B.: A metabolic disorder similar to Zellweger syndrome with hepatic acatalasia and absence of peroxisomes, altered content and redox state of cytochromes and infantile cirrhosis with hemosiderosis. Eur. J. Pediatr., 124: 261 (1977).

40. The authors thank Ms. Angela Liu and Surinder K. Khangoora for their technical assistance.

41. Requests for reprints should be addressed to: Dr. Inderjit Singh, John F Kennedy Institute, 707 N. Broadway, Baltimore, MD 21205.

42. Supported in part by grants BNS-8240546 from the National Science Foundation and HD 10981 from the United States Public Health Service.

43. Received for publication December 14, 1982.

44. Accepted for publication May 11, 1983

\title{
A Comparison between Electrical Impedance and Strain Gauge Plethysmography for the Study of Cerebral Blood Flow in the Newborn
}

\author{
KATE COSTELOE, ${ }^{(24)}$ DIANE P. L. SMYTH, N. MURDOCH, ${ }^{(24)}$ P. ROLFE, ${ }^{(25)}$ AND J. P. M. TIZARD \\ University Department of Paediatrics, John Radcliffe Hospital, Headington, Oxford, England
}

\section{Summary}

This study investigates the possibility of using pulsatile transcephalic impedance changes, $\Delta Z$, for the continuous monitoring of cerebral blood flow, $\mathrm{CBF}$, in the sick newborn infant. The performance of the impedance method is compared with the measurement of cranial flow, Fc, using a strain gauge for detecting the predicted changes in cerebral blood flow when the baby breathes $2 \% \mathrm{CO}_{2}$ in air, or $\mathrm{O}_{2}$.

In all five studies in which measurements were compared in air and $\mathrm{CO}_{2}$ the expected increases in $\mathrm{Fc}$ and $\Delta \mathrm{Z}$ were seen. In six of seven studies comparing measurements in air and $\mathrm{O}_{2}$ the expected fall in the variables was seen, indicating reduced cerebral blood flow. The problems of both these methods are discussed and we conclude that the impedance method is as good as the strain gauge method for detecting changes in cerebral blood flow.

\section{Abbreviations}

CAT, computerized axial tomography

CBF, cerebral blood flow

CBFa, apparent cerebral blood flow

$\mathrm{CV}$, coefficient of variation

Fc, cranial flow

IVH, intraventricular hemorrhage

OFC, occipitofrontal circumference

$\mathrm{PsO}_{2}$, skin surface oxygen partial pressure

$\Delta Z$, height of pulsatile impedance signal

Zo ohm, transcephalic impedence

IVH remains a major cause of death and of handicap amongst the survivors of neonatal intensive care $(17,18)$. The introduction of CAT and ultrasound scanning of the brain has facilitated improved diagnosis and grading of $\operatorname{IVH}(17,19)$, and studies have identified clinical and physiologic factors that may be associated with its pathogenesis $(7,10)$. More detailed analyses of the physiologic conditions, particularly with reference to intracerebral haemodynamics preceding IVH, have been few. Most of the measurements of CBF that have been made in preterm infants have resulted from studies using radioactively labeled xenon, $(11,12)$. It is not possible to make repeated measurements in an individual baby using this method and in the United Kingdom the technique is generally regarded as unethical. There is a need to establish a safe, non-invasive method for the continuous monitoring of $\mathrm{CBF}$.

The use of several non-invasive methods for obtaining information related to $\mathrm{CBF}$ in newborn infants has been described in the literature. These include 1) monitoring intracranial pressure by placing a transducer over the anterior fontanelle (22), 2) using ultrasound to measure blood flow velocity in the anterior cerebral artery $(1,2)$, and 3) jugular venous occlusion plethysmography using a strain gauge around the $\operatorname{OFC}(3,4)$.

Intracranial pressure can be measured continuously, but we believe it to be of limited value as changes in CBF are not directly reflected by changes in intracranial pressure. Doppler ultrasound gives only a highly indirect indication of flow by measuring the pulsatility index which, by comparing systolic and diastolic blood flow velocities, gives an estimate of the vascular resistance.

Strain gauge measurements can only be intermittent and the quantitative accuracy is limited. The strain gauge method has been shown to detect an increase of CBF in response to inhaled $2 \% \mathrm{CO}_{2}$ in air, and a decrease of $\mathrm{CBF}$ in response to inhaled $100 \%$ oxygen in the newborn baby $(9,21)$.

We have previously investigated the suitability of electrical impedance plethysmography for the measurement of cardiac output (5) and limb blood flow (6) in the newborn and found that a reliable continuous estimate of flow can be made. Many workers have collected pulsatile electrical impedance data from the adult human head (8). Namon et al. (15) found that the height of the pulsatile impedance signal varies linearly with respect to $\mathrm{CBF}$. The method has been used to monitor changes in the CBF of individuals passing between different sleep states (13), and during the inhalation of increasing $\mathrm{CO}_{2}$ concentrations 
(15). This communication investigates the applicability and validity of this method in sick newborns by comparing the performance of the impedance and strain gauge methods in following the changes in $\mathrm{CBF}$ in individual babies while breathing room air, $2 \% \mathrm{CO}_{2}$ in air, and $100 \%$ oxygen.

\section{MATERIALS AND METHODS}

Electrical impedance measurements. A 4-electrode impedance system was used. Pairs of flat German silver disc electrodes, 0.8 $\mathrm{cm}$ in diameter, were mounted on adhesive tape, (Blenderm $3 \mathrm{M}$ ) so that the distance between their centres was $2.5 \mathrm{~cm}$. The electrodes were applied to the baby on the OFC using electrode jelly (Cambridge Electrode Jelly), one pair being placed over the centre of the forehead and the other over the occiput. The instrument used in this study was the same as that used in a previous study of limb blood flow (6). It produced a constant amplitude sinusoidal alternating current of $2 \mathrm{~mA} \mathrm{rms}$ at 100 $\mathrm{kHz}$ and had an output impedance of $13 \mathrm{Kohms}$. The current was applied between one of an electrode pair and the contralateral electrode of the other pair. The voltage representing the electrical impedance was recorded between the remaining contralateral electrode pair (Fig. 1).

Strain gauge measurements. A mercury-in-rubber strain gauge was used (3). The strain gauge was positioned on the OFC over the impedance electrodes (Fig. 2). Venous occlusion plethysmography was performed as has been described previously (3), and the gauge was calibrated in situ using a pneumatic calibrating device.

Gas measurements. $\mathrm{CO}_{2}$ concentrations were analysed continuously throughout each study via a small silastic nasal catheter using a mass spectrometer (MS2, Cyprane Ltd.). Measurements of end tidal $\mathrm{CO}_{2}$ were made from breaths in which there was a good plateau of $\mathrm{CO}_{2}$ concentration. Under these conditions, end tidal $\mathrm{CO}_{2}$ is equivalent to alveolar $\mathrm{CO}_{2}, \mathrm{PACO}_{2} . \mathrm{PSO}_{2}$ was measured continuously using a Radiometer electrode, (TCM 1), on the anterior abdominal wall, the electrode being maintained at $43.5^{\circ} \mathrm{C}$

Recordings. Recordings of ECG, pulsatile impedance, $\Delta \mathrm{Z}$, ohm, strain gauge output and the respiratory $\mathrm{CO}_{2}$ concentrations were made using a 4-channel Hewlett Packard direct writing recorder, type 7404A. Pulsatile recordings were made with a paper speed of $2.5 \mathrm{~cm} / \mathrm{s}$ and venous occlusions at $1 \mathrm{~cm} / \mathrm{s}$. Zo

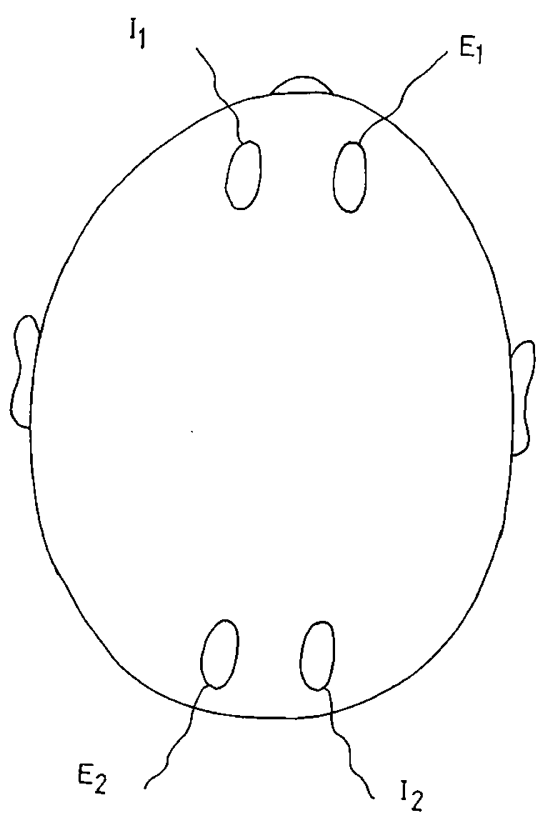

Fig. 1. Diagram to show impedance electrode configuration. $I_{1}$ and $I_{2}$, current electrodes and $E_{1}$ and $E_{2}$, potential electrodes.

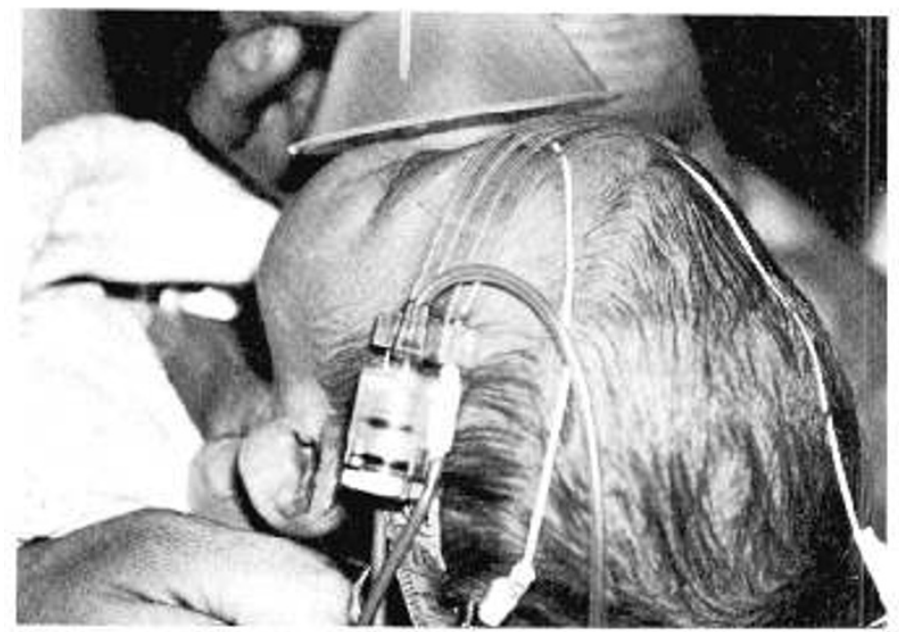

Fig. 2. Baby with impedance electrodes and strain gauge in position breathing $2 \% \mathrm{CO}_{2}$ via the funnel.

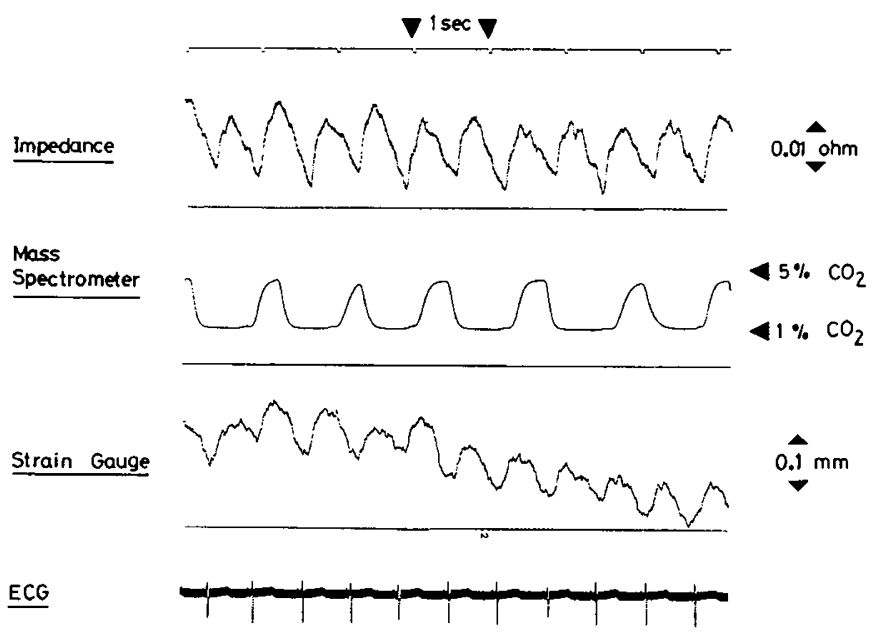

Fig. 3. Pulsatile signal recording.

ohm and $\mathrm{PsO}_{2}$ were noted throughout the study at frequent intervals.

Experimental procedure. Each baby was brought to the laboratory immediately after a feed, the transducers were attached, the baby was then swaddled in the hope, usually fulfilled, that it would sleep throughout the study period. A mixture of $2 \% \mathrm{CO}_{2}$, $21 \%$ oxygen, and $77 \%$ nitrogen, $\left(2 \% \mathrm{CO}_{2}\right)$ and $100 \%$ oxygen were administered via a polythene funnel held over the baby's muzzle area, but clear of the skin (Fig. 2). Each baby was studied breathing gases in the sequence: air; $2 \% \mathrm{CO}_{2}$ :air; $100 \%$ oxygen. No measurements were made until the baby had been breathing the relevant gas for at least $5 \mathrm{~min}$.

We found that the end tidal $\mathrm{CO}_{2}$, while breathing $2 \% \mathrm{CO}_{2}$, and $\mathrm{PsO}_{2}$, while breathing $100 \%$ oxygen, had always stabilised by this time. From the third study onward, the signal from the mass spectrometer was displayed alongside the impedance and strain gauge signals so that it was seen that the baby had received a steady supply of $2 \% \mathrm{CO}_{2}$ before any recordings were made. We found it necessary to allow the oxygen to flow into the mask at $10 \mathrm{l} / \mathrm{min}$ to prevent a significant build-up of $\mathrm{CO}_{2}$ within the funnel. As soon as a satisfactory recording of impedance pulsations had been obtained, venous occlusion plethysmography was performed. We tried to achieve at least 10 satisfactory occlusions in each gas.

\section{ANALYSIS OF RECORDINGS}

Electrical impedance measurements. The baseline of the pulsatile impedance record usually followed breathing (Fig. 3). In 
order to compensate for this, the maximum impedance, pulse height was taken as the height from the peak of the impedance pulse to a line drawn from the beginning to the end of the pulse. Ten consecutive pulses were analysed from each trace before venous occlusion. It was possible to analyse impedance pulses between individual venous occlusions and this was done in each gas.

Strain gauge measurements. Cerebral blood flow was calculated from the strain gauge recordings as has been described previously from this Department (3). The traces were then analysed in the method described by Cross et al. (4), which fits exponential curves to the inflow and outflow phases of the occlusions. This enables the calculation of a value for total Fc to be made where:

$$
\mathrm{Fc}=\mathrm{CBFa} \cdot \frac{\mathrm{Ki}}{\mathrm{Ki}-\mathrm{Ko}} \mathrm{ml} \cdot 100 \mathrm{ml} \mathrm{brain}^{-1} \cdot{\mathrm{min}^{-1}}^{-1}
$$

where CBFa represents the flow calculated from the slope of the first pulse of the occlusion slope; $\mathrm{Ki}$, time constant of the exponential curve of the inflow slope; and $\mathrm{Ko}$, time constant of the exponential curve of the outflow slope. Whenever possible at least 10 occlusions in each gas were analysed in this way and a mean value for $\mathrm{Fc}$ was calculated.

Reproducibility. The reproducibility of the pulsatile impedance and strain gauge measurements was investigated by calculating the $\mathrm{CV}$ of the pulses measured in each gas mixture in each baby:

$$
\mathrm{CV}=\frac{\mathrm{SD}}{\mathrm{mean}} \times 100 \%
$$

Subjects. The babies studied were all full-term healthy infants born in the John Radcliffe Hospital. The study was approved by the Hospital Ethics Committee. The procedure was explained in detail, always to the mother and usually to both parents, and written consent was obtained. The mother was encouraged to and usually did attend the study.

\section{RESULTS}

A total of 12 babies was studied. Four of these yielded no useful comparative data: three never settled down and although the fourth was less restless, the impedance trace was very noisy throughout and not suitable for analysis. The mean age of the remaining eight babies was $4 \mathrm{~d}$ (range, 3-8 d), and the mean weight was $3406 \mathrm{~g}$ (range, $2825-4130 \mathrm{~g}$ ). Measurements in all three respiratory gases were made in seven babies; in the eighth (baby Mo, Table 1), the impedance trace was intermittently noisy and the record made during $100 \%$ oxygen breathing was not analysed. The measurements made in $\mathrm{CO}_{2}$ in baby $\mathrm{Ca}$ were discarded as a brief power cut early in the study resulted in a loss of vacuum in the mass spectrometer with ensuing inability to measure respiratory $\mathrm{CO}_{2}$.

During the first two studies the signal from the mass spectrometer was displayed on a second pen recorder that was not visible to those making the measurements. Upon analysing the measurements, we realised that these babies, (Ba and St, Table 1), had received variable $\mathrm{CO}_{2}$ concentrations. In the case of Baby $\mathrm{Ba}$, the administered $\mathrm{CO}_{2}$ concentrations ranged between $0.3-1.6 \%$ and that to baby St was between 1.4-2.4\%. Baby Ba showed no change in end tidal $\mathrm{CO}_{2}$, whereas that of Baby St rose by only $1.8 \mathrm{~mm} \mathrm{Hg}$. The increase in end tidal $\mathrm{CO}_{2}$ seen in those babies known to have received a steady supply of $2 \% \mathrm{CO}_{2}$ ranged between $3.5-7.9 \mathrm{~mm} \mathrm{Hg}$.

Room air was breathed directly from the room while both $2 \%$ $\mathrm{CO}_{2}$ and $100 \% \mathrm{O}_{2}$ were administered via a funnel. There were no obvious changes of respiratory pattern while changing from one method of gas delivery to the other, and it is not considered that any changes in CBF noted are attributable to this difference.

In summary, useful data in $\mathrm{CO}_{2}$ was recorded from seven babies, two of these ( $\mathrm{Ba}$ and $\mathrm{St}$ ) are known not to have received a steady supply of $2 \% \mathrm{CO}_{2}$. Useful data in $100 \%$ oxygen were recorded from these seven babies in one of whom (Baby $\mathrm{Su}$ ) it was not possible to measure $\mathrm{PsO}_{2}$.

Paired $t$ tests were performed in order to compare the meas-

\begin{tabular}{|c|c|c|c|c|c|c|c|c|}
\hline Subject & Gas & $\mathrm{PACO}_{2}$ & Zo & $\dot{\mathbf{H}}$ & $\Delta \mathrm{Z}$ & $\begin{array}{l}\% \text { change } \\
\Delta \mathrm{Z} \text { from } \\
\Delta \mathrm{Z} \text { in air }\end{array}$ & $\mathrm{Fc}$ & $\begin{array}{l}\% \text { change } \\
\text { Fc from } \\
F c \text { in air }\end{array}$ \\
\hline \multirow[t]{3}{*}{$\mathrm{Ba}$} & Air & 35.5 & 37 & 128 & 0.0090 & & 41.1 & \\
\hline & $\mathrm{CO}_{2}$ & 35.5 & 37 & 127 & 0.0082 & -8.9 & 38.9 & -5.4 \\
\hline & $\mathrm{O}_{2}$ & $\ldots$ & 36 & 131 & 0.0067 & -25.6 & 35.7 & -13.1 \\
\hline \multirow[t]{3}{*}{ St } & Air & 44.4 & 34 & 125 & 0.0124 & & 26.8 & $\ldots$ \\
\hline & $\mathrm{CO}_{2}$ & 46.2 & 33 & 115 & 0.0125 & +0.8 & 20.9 & -22.0 \\
\hline & $\mathrm{O}_{2}$ & $\ldots$ & 33 & 113 & 0.0100 & -19.4 & 23.1 & -13.8 \\
\hline \multirow[t]{3}{*}{$\mathrm{Su}$} & Air & 35.5 & 32 & 127 & 0.0150 & $\ldots$ & 23.4 & $\ldots$ \\
\hline & $\mathrm{CO}_{2}$ & 42.6 & 32 & 129 & 0.0159 & +6.0 & 24.0 & +2.6 \\
\hline & $\mathrm{O}_{2}$ & $\ldots$ & 31 & 126 & 0.0095 & -36.7 & 21.0 & -10.3 \\
\hline \multirow[t]{3}{*}{ Wi } & Air & 32.0 & 31.5 & 121 & 0.0066 & $\ldots$ & 19.8 & $\ldots$ \\
\hline & $\mathrm{CO}_{2}$ & 35.5 & 31 & 118 & 0.0098 & +48.5 & 22.0 & +11.1 \\
\hline & $\mathrm{O}_{2}$ & $\cdots$ & 31 & 108 & 0.0059 & -10.6 & 27.1 & +36.9 \\
\hline \multirow[t]{2}{*}{$\mathrm{Ca}$} & Air & $\ldots$ & 35.5 & 112 & 0.0141 & $\ldots$ & 21.8 & $\cdots$ \\
\hline & $\mathrm{O}_{2}$ & $\cdots$ & 35 & 97 & 0.0096 & -31.9 & 15.8 & -27.5 \\
\hline \multirow[t]{3}{*}{ Ro } & Air & 34.1 & 44 & 120 & 0.0150 & $\ldots$ & 32.3 & $\cdots$ \\
\hline & $\mathrm{CO}_{2}$ & 41.2 & 44 & 120 & 0.0176 & +17.3 & 38.0 & +17.6 \\
\hline & $\mathrm{O}_{2}$ & $\ldots$ & 44 & 111 & 0.0139 & -7.3 & 23.6 & -26.9 \\
\hline \multirow[t]{3}{*}{ Mo } & Air & 31.2 & 33 & 112 & 0.0079 & $\ldots$ & 31.5 & $\ldots$ \\
\hline & $\mathrm{CO}_{2}$ & 39.1 & 33 & 125 & 0.0102 & +29.1 & 36.6 & +16.2 \\
\hline & $\mathrm{O}_{2}$ & $\ldots$ & 33 & $\ldots$ & & $\ldots$ & & $\ldots$ \\
\hline \multirow[t]{3}{*}{$\mathrm{Ma}$} & Air & 27.0 & 36 & 95 & 0.0203 & $\ldots$ & 30.3 & $\ldots$ \\
\hline & $\mathrm{CO}_{2}$ & 31.2 & 36 & 110 & 0.0222 & +9.4 & 35.2 & +16.2 \\
\hline & $\mathrm{O}_{2}$ & $\ldots$ & 35 & 89 & 0.0196 & -4.9 & 28.9 & -4.6 \\
\hline
\end{tabular}

Table 1. Results of measurements made from eight babies breathing air, $\mathrm{CO}_{2}$, and $\mathrm{O}_{2}$

* Abbreviations: $\mathrm{PACO}_{2}$, alveolar $\mathrm{CO}_{2}$ tension (mm Hg); Zo, mean transcephalic impedance $(\Omega) ; \mathrm{H}$, heart rate, (beat/min); $\Delta \mathrm{Z}$, pulsatile impedance change $(\Omega)$; and $\mathrm{Fc}$, total cranial flow $\left(\mathrm{ml} \cdot 100 \mathrm{ml}\right.$ brain tissue $\left.{ }^{-1} \cdot \mathrm{min}^{-1}\right)$. 


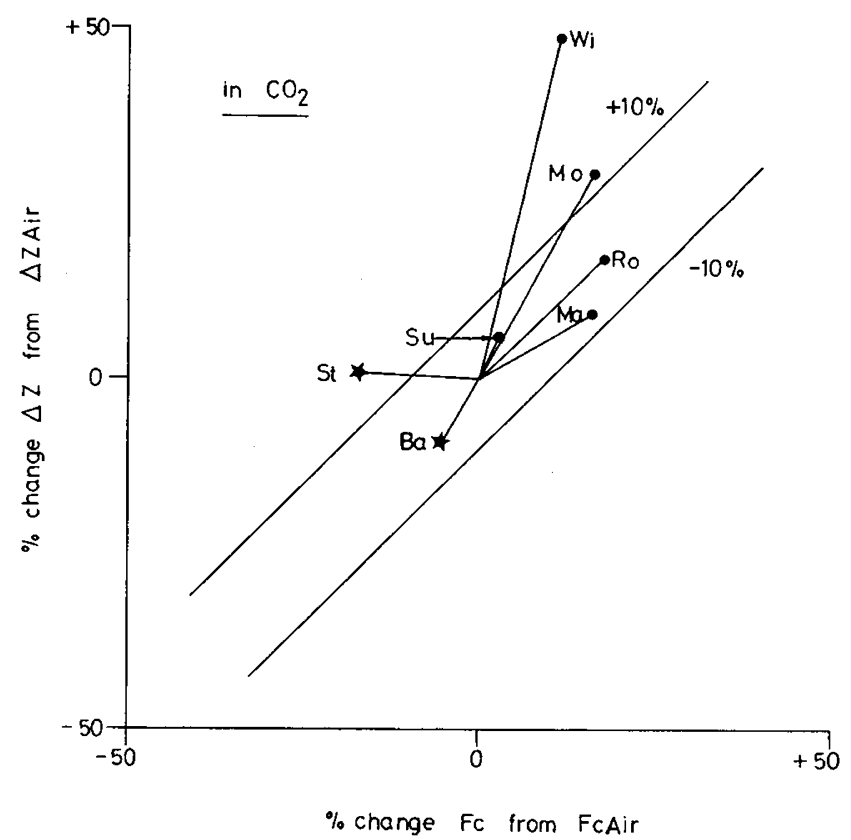

Fig. 4. Results in $\mathrm{CO}_{2}$. Babies indicated by symbol $\bullet$ known to have received $2 \% \mathrm{CO}_{2}$ for $5 \mathrm{~min}$. Babies indicated by $\star$ are known to have received varying $\mathrm{CO}_{2}$ concentration.

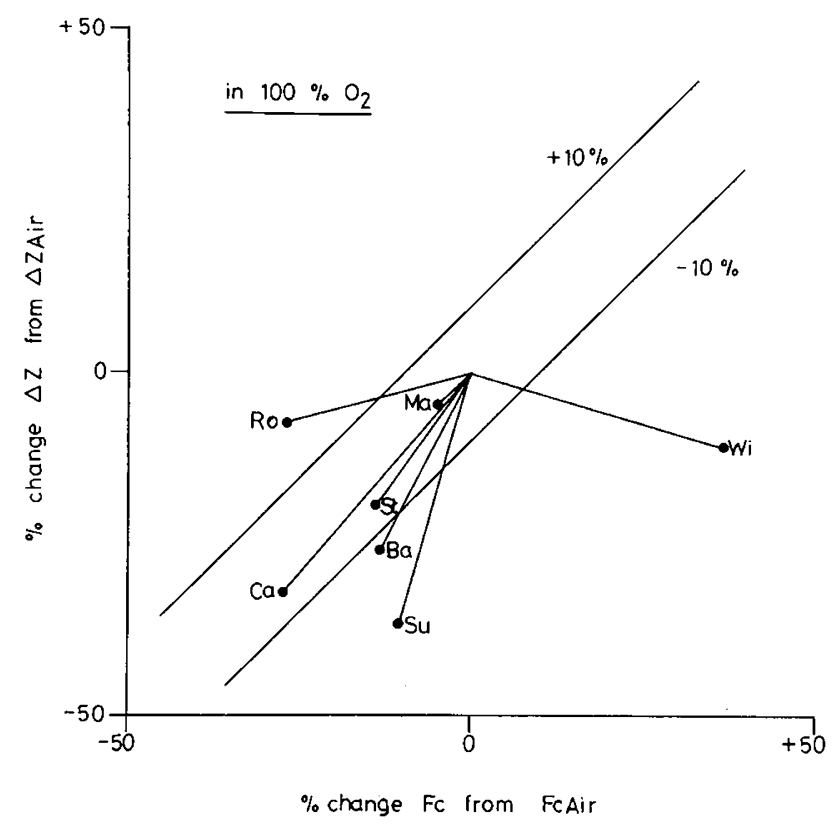

Fig. 5. Results in $100 \% \mathrm{O}_{2}$.

urements of impedance pulse height measured before and between occlusions in each gas in each baby and there was no significant difference between these values $(P>0.1)$. Neither was there any significant difference in the pulsatile impedance measurements nor the strain gauge measurements made in air before $\mathrm{CO}_{2}$ administration, compared with those made in air between $\mathrm{CO}_{2}$ and $100 \%$ oxygen administration, $P>0.1$. These measurements were, therefore, used together and the values for impedance pulse height given below are the mean values of the measurements made before and during the occlusion phase of the experiment, whereas the $\Delta \mathrm{Z}$ and $\mathrm{Fc}$ values in air are the means of all measurements made before and after $\mathrm{CO}_{2}$ administration. These results are shown in Table 1 , expressed both in absolute terms and as a percentage change from the mean value in air, and are seen graphically in Figures 4 and 5. Transcephalic impedance, Zo Ohm, was stable throughout each study.

Results in $\mathrm{CO}_{2}$. The measurements made from the two babies ( $\mathrm{Ba}$ and $\mathrm{St}$ ), who were known to have received variable $\mathrm{CO}_{2}$ concentrations and who had had either no increase or a small increase in end tidal $\mathrm{CO}_{2}$, showed that there was a decrease in both $\mathrm{Fc}$ and $\Delta \mathrm{Z}$ in Baby $\mathrm{Ba}$ and a decrease in $\mathrm{Fc}$ of $22 \%$ in Baby St, the decrease in the latter case being associated with a small $(0.8 \%)$ increase in $\Delta \mathrm{Z}$. Both variables, $\Delta \mathrm{Z}$ and $\mathrm{Fc}$, increased as expected in the five babies known to have received $2 \% \mathrm{CO}_{2}$ for $5 \mathrm{~min}$. In these five babies, the mean $\Delta \mathrm{Z}$ per $\mathrm{mm} \mathrm{Hg}$ increase in end-tidal $\mathrm{CO}_{2}$ was $4.5 \%$, whereas that of $\mathrm{Fc}$ was $2.4 \%$.

Results in $100 \%$ oxygen. Six of the seven pairs of measurements made in $100 \%$ oxygen showed a fall in both $\mathrm{Fc}$ and $\Delta \mathrm{Z}$. The seventh study, Baby Wi, indicated the expected decrease in $\Delta Z,(-10.6 \%)$, but a large increase of $36.9 \%$ in Fc. This study is discussed below. The mean percentage change in $\Delta \mathrm{Z}$ in $100 \%$ oxygen was $-19.5 \%$ whereas the mean change in $\mathrm{Fc}$ was $-8.5 \%$. If the strain gauge result from Baby Wi is excluded, the change in $\mathrm{Fc}$ is $-16 \%$.

Reproducibility. The reproducibility of the variables Fc and $\Delta \mathrm{Z}$ is summarised in Table 2.

\section{DISCUSSION}

This study attempts to validate the use of electrical impedance plethysmography for continuous estimation of CBF in the newborn by comparing its performance in following the expected changes of $\mathrm{CBF}$ in response to breathing $2 \% \mathrm{CO}_{2}$ and $100 \%$ oxygen with that of jugular venous occlusion plethysmography using a strain gauge. The results of this study are very encouraging. In all five studies in which the baby was known to have received a steady concentration of $2 \% \mathrm{CO}_{2}$ for $5 \mathrm{~min}$ before recordings were made, the expected increases in $\mathrm{Fc}$ and $\Delta \mathrm{Z}$, believed to indicate increased CBF, were seen. In six of seven studies using $100 \%$ oxygen a fall in those variables was seen indicating reduced $\mathrm{CBF}$. Four of the seven $\mathrm{CO}_{2}$ studies and three of the seven oxygen studies showed a change of $\Delta \mathrm{Z}$ within $\pm 10 \%$ of the percentage change of $\mathrm{Fc}$.

The technique of jugular venous occlusion plethysmography using a strain gauge around the OFC was chosen as the method with which to compare the impedance method, as it is the only non-invasive method currently available that has been used to give a quantitative estimate of $\mathrm{CBF}$ in the newborn. The strain gauge method has never itself been evaluated against any other more direct measurement, although it has been used to detect changes in CBF in individual babies. The values calculated for CBF using this method are usually lower than values obtained using invasive techniques, the latter of which is believed to be more accurate. The low values obtained when making strain gauge measurements are thought to be due, predominantly, to the low compliance of the skull limiting the expansion of the head during occlusion and to a lesser extent to the presence of unoccluded venous channels and to the anisotropic character of skull expansion (3). The effect of the unoccluded venous channels should be overcome by using the method of analysis described

Table 2. Reproducibility of measurements of cranial flow, Fc, and the pulsatile impedence signal, $\Delta Z$

\begin{tabular}{|c|c|c|c|c|c|c|}
\hline \multirow{3}{*}{$\begin{array}{l}\text { Measurement } \\
\text { made in }\end{array}$} & \multicolumn{6}{|c|}{$\%$ Coefficient of variation } \\
\hline & \multicolumn{3}{|c|}{$\mathrm{Fc}$} & \multicolumn{3}{|c|}{$\Delta \mathrm{Z}$} \\
\hline & $\bar{x}$ & Range & $n$ & $\bar{x}$ & Range & $n$ \\
\hline Air & 11.9 & $6.8-16.5$ & 8 & 16.3 & $12.8-21.3$ & 8 \\
\hline $\mathrm{CO}_{2}$ & 13.5 & $7.7-22.7$ & 8 & 18.4 & $14.7-24.4$ & 8 \\
\hline $\mathrm{O}_{2}$ & 14.9 & $11.1-18.8$ & 7 & 19.8 & $14.8-26.2$ & 7 \\
\hline
\end{tabular}

* Abbreviations: Fc, cranial flow, measured by strain gauge with jugular venous occlusion and $\Delta \mathrm{Z}$, pulsatile impedence signal. 
by Cross et al. (4), which takes account of the slope of the strain gauge signal both during and immediately upon release of venous occlusion. The more important effect of skull compliance is likely to vary widely between different babies as the fontanelle size and the degree of suture separation varies. This effect results in the strain gauge method being unsuitable for making comparative measurements of blood flow between different babies. It is for this reason that the present study comparing the two methods in a small group of babies was undertaken while changing the $\mathrm{CBF}$ by altering the inhaled $\mathrm{CO}_{2}$ and the oxygen concentrations and then considering the results in each baby individually.

It has been shown previously that full-term babies given a steady supply of $0.5 \% \mathrm{CO}_{2}$ to breathe show unpredictable changes of $\mathrm{CBF}$ as measured by the strain gauge (21), and this would seem to explain the results of babies $\mathrm{Ba}$ and $\mathrm{St}$, neither of whom showed a significant increase in end tidal $\mathrm{CO}_{2}$. The increases of $\Delta \mathrm{Z}$ and $\mathrm{Fc}$ per $\mathrm{mm} \mathrm{Hg}$ increase of alveolar $\mathrm{CO}_{2}$ in those babies who received $2 \% \mathrm{CO}_{2}$ of $4.5 \%$ and $2.4 \%$, respectively are lower than the $7.8 \%$ increase found using the strain gauge method by Leahy et al. (9). The end tidal $\mathrm{CO}_{2}$ was not measured in the study by Rahilly (21) but the proportional increases in CBF while breathing $2 \% \mathrm{CO}_{2}$ were higher than in the present study, ranging from $21-170 \%$ as opposed to $2.6-$ $26 \%$ using $\mathrm{Fc}$ and from $6-48.5 \%$ using $\Delta \mathrm{Z}$ in the present study. Why the response of the cerebral vasculature to an increase of inspired $\mathrm{CO}_{2}$ should be less in the present group of babies is not clear; the changes found by the other workers do seem to be very high. Oleson et al. (16), working with adult humans and using an invasive method using radioactive labeled xenon, suggest that there is a $4 \%$ increase of $\mathrm{CBF}$ per $\mathrm{mm} \mathrm{Hg}$ increase of arterial $\mathrm{CO}_{2}$ tension, this result being closer to that of the present study.

The results in $100 \%$ oxygen are very encouraging, the only unpredicted finding was the apparent increase in Fc seen in Baby Wi. It has not been possible to explain this finding. There is no doubt that this child received adequate oxygen as the $\mathrm{PsO}_{2}$ was recording $330 \mathrm{~mm} \mathrm{Hg}$ at the time of these measurements. There is a question as to whether the strain gauge might have slipped but the mechanical calibration produced the same signal throughout the study. The percentage change of $\Delta Z$ in $100 \%$ oxygen of $-19.5 \%$ and the change of $\mathrm{Fc}$ of $-16 \%$ (considering the data with the result from Baby Wi excluded) compare favourably with $-15 \%$ found by Leahy et al. (9) both results being less than $-32.8 \%$ of Rahilly (21).

Although the direction of the measured changes of Fc and $\Delta \mathrm{Z}$ in this study were largely as expected, in only seven out of 14 studies was the observed change in $\Delta \mathrm{Z}$ between $\pm 10 \%$ of the change of Fc. It is not known how the compliance of an individual baby's head varies as the CBF in that child changes and it is not known if the apparent changes of flow detected by the strain gauge method are linearly related to the true changes of flow; it is possible that they are not. This consideration may in some part account for the failure of the methods to show quantitatively similar changes. This failure is also attributable to the impedance method both in regard to technical aspects and to the comparatively poor reproducibility found in this study (Table 2). It is an oversimplification to consider the pulsatile impedance signals to be due solely to the pulsatile blood volume changes within the brain. There are other significant contributions to this signal which are unlikely to change in a linear fashion with the true CBF. The most important of these are the contributions from the extra-cerebral circulation, which have been found to be up to $20 \%$ of the total signal in adults (23), and the effect of change of red cell orientation and acceleration associated with arterial pulsations, which has been estimated to represent up to $15 \%$ of the total signal (20).

The most significant problems that we found while using the impedance method are those of noisy signals and of poor beatto-beat reproducibility. We believe that this is a problem of electrical contact in certain babies. We tried different electrodes, but regardless of type used, there were babies from whom it was impossible to obtain satisfactory records, despite their being still.
Why this should be is not obvious, but it does not constitute a major objection to the use of cerebral impedance. The problem of poor reproducibility is a more significant threat to the clinical usefulness of the method as it makes the masking of changes of the CBF more likely.

The wide variation of beat-to-beat measurements of $\Delta \mathrm{Z}$ in this study was due both to gross body and respiratory-related movements. The mean values for $\Delta \mathrm{Z}$ were calculated from at least 15 pulses and it is obviously important that such numbers of pulses are analysed if meaningful assessments of CBF are to be made. It should be remembered that the babies from whom these data were collected were all healthy full-term infants and it is apparent from studies currently being performed on smaller, sick babies, that these less active subjects yield more stable impedance traces. The manual analysis of large numbers of pulses as was done in this study was very time consuming and would limit the feasibility of using this method for long studies of babies under intensive care; the analysis may, however, be automated easily using a microcomputer. One criticism of the impedance method is that it cannot, in the present state of knowledge, give a quantitative measurement of CBF but can only be used to detect changes of flow in an individual baby. This criticism can also be made of the other non-invasive techniques. Numerical values for flow have been calculated from strain gauge measurements, but these cannot be accurate because of the limitations of the method discussed above. We are developing an electrical model of the newborn head to predict electrical impedance changes recorded at the surface in response to changes of the intra-cerebral contents (14). Using this model it may be possible to relate impedance changes such as those seen in this study to changes in intracerebral blood volume.

We have found that it is easy to make pulsatile cerebral impedance measurements in the majority of newborn babies. The method is easier to perform than the venous occlusion plethysmography using the strain gauge and the results are as good. It involves less interference with the baby and is therefore potentially more suitable for the study of babies under intensive care. We believe that the impedance method has more potential than Doppler ultrasound for making continuous long term recordings such as are needed to elucidate changes in CBF associated with the events which may be involved in the pathogenesis of IVH.

\section{REFERENCES AND NOTES}

1. Bada, H. S., Hajjar, W., Chua, C., and Sumner, D. S.: Non-invasive diagnosis of neonatal aspyhxia and intraventricular haemorrhage by doppler ultrasound. J. Pediatr., 95: 775 (1979)

2. Bada, H. S., Milner, J. E., Menke, J. A., Bashiru, M., Binstadt, D., Sumner, D. S., and Khanna, N. N.: Intracranial pressure and cerebral artery pulsatile flow measurements in neonatal intraventricular haemorrhage. J. Paeditr. 100: 291 (1982).

3. Cooke, R. W. I., Rolfe, P., and Howat, P.: A technique for the non-invasive estimation of cerebral blood flow in the newborn infant. J. Med. Eng. Tech., 1: 263 (1977).

4. Cross, K. W., Dear, P. R. F., Hathorn, M. K. S., Hyams, A., Kerslake, D. McK., Milligan, D. W. A., Rahilly, P. M., and Stothers, J. K.: An estimation of intracranial blood flow in the newborn infant. J. Physiol., 289: 329 (1979).

5. Costeloe, K., Stocks, J., Godfrey, S., Mohapatra, S. N., and Hill, D. W.: Cardiac output in the neonatal period using impedance cardiography. Pediatr. Res. 11: 1171 (1977).

6. Costeloe, K. and Rolfe, P.: Continuous limb blood flow estimation in the newborn using electrical impedance plethysmography. Pediatr. Res., 14 . $1053(1980)$

7. Fujimura, M., Salisbury, D. M., Robinson, R. O., Howat, P., Emerson, P. M., Keeling, J. W., and Tizard, J. P. M.: Clinical events relating to intraventricular haemorrhage in the newborn. Arch. Dis. Child., 54: 409 (1979).

8. Hadjiev, D.: Impedance methods for investigation of cerebral circulation. In: J. S. Meyer and J. P. Schade: Progress in Brain Research, 35: 25. Cerebral Blood Flow. Elsevier Publishing Company, Amsterdam/London/New York (1972).

9. Leahy, F. A. N., Cates, D., MacCallum, M. and Rigatto, H.: Effect of $\mathrm{CO}_{2}$ and $100 \% \mathrm{O}_{2}$ on cerebral blood flow in preterm infants. J. Appl. Phys.: Respir. Environ. Exer. Physiol., 48(3): 468 (1980).

10. Lipscomb, A. P., Thorburn, R. J., Reynolds, E. O. R., Stewart, A. L., Blackwell, R. J., Cusick, G., and Whitehead, M. D.: Pneumothorax and cerebral haemorrhage in preterm infants. Lancet, $1: 414$ (1981).

11. Lou, H. C., Lassen, N. A., Friis-Hansen, B.: Decreased cerebral blood flow 
after administration of sodium bicarbonate in the distressed newborn infant. Acta Neurol. Scand., 57: 239 (1978).

12. Lou, H. C., Lassen, N. A., and Friis-Hansen, B.: Impaired autoregulation of cerebral blood flow in the distressed newborn infant. J. Pediatr., 94: 118 (1979).

13. Lovett Doust, J. W. and Lovett Doust, J. N.: Aspects of the cerebral circulation during non-REM sleep in healthy controls and psychiatric patients, as shown by rheoencephalography. Psychophysiology, 12: 493 (1975).

14. Murray, P. W.: Field calculations in the head of a newborn infant and their application to the interpretation of transcephalic impedance measurements. Med. Biol. Eng. Comput., 19: 538 (1981).

15. Namon, R., Gollan, F., Shimojyo, S., Sano, R. M., Markovich, S. E., and Scheinberg, P.: Basic studies in rheoencephalography. Neurology, 17: 239 (1967).

16. Oleson, J., Paulson, O. B., and Lassen, N. A.: Regional cerebral blood flow in man determined by the initial slope of the clearance of intra-arterially injected ${ }^{133}$ Xe. Stroke, 2: 519 (1971).

17. Pape, K. E., Blackwell, R. J., Cusick, G., Sherwood, A., Houang, M. T. W., Thorburn, R. J., and Reynolds, E. O. R.: Ultrasound detection of brain damage in preterm infants. Lancet, $1: 1261$ (1979).

18. Pape, K. E. and Wigglesworth, J. S.: Haemorrhage, ischaemia and the perinatal brain. Clinics in Developmental Medicine, London: Publ. Heinemann, for Spastics International Medical Publications. (1979).

19. Papile, L-A., Burstein, J., Burstein, R., and Koffler, H.: Incidence and evolution of subependymal and intraventricular haemorrhage: a study of infants with birthweights less than 1500 gm. J. Pediatr., 92: 529 (1978).

20. Peura, R. A., Wheeler, W. H., Renney, B. C., and Arcuri, J.: Impedance plethysmography: relative contribution of blood volume and red cell velocity changes on the signal strength. Digest of the 11 th. International Conference of Medical and Biological Engineering. Ottawa, Canada, 240 (1976).

21. Rahilly, P. M.: Effects of $2 \%$ carbon dioxide, $0.5 \%$ carbon dioxide and $100 \%$ oxygen on cranial blood flow of the human neonate. Pediatrics, 66:685 (1980).

22. Robinson, R. O., Rolfe, P., and Sutton, P.: Non-invasive method for measuring intracranial pressure in normal newborn infants. Dev. Med. Child. Neurol., 19: 305 (1977).

23. Weindling A. M., Murdoch, N., and Rolfe, P.: The effect of electrode size on the contributions of intracranial and extracranial blood flow to the cerebral electrical impedance plethysmogram. Med. Biol. Eng. Comput., 20: 545 (1982).

24. Received for publication July $26,1982$.

25. Accepted for publication April 8, 1983.

\title{
Short Communication. Role of Agar Beads in the Pathogenicity of Pseudomonas aeruginosa in the Rat Respiratory Tract
}

\author{
MARCELO C. NACUCCHIO, ${ }^{(10)}$ M. CRISTINA CERQUETTI, ROBERTO P. MEISS, AND \\ DANIEL O. SORDELLI \\ Facultad de Farmacia y Bioquímica, Universidad de Buenos Aires, Argentina
}

\section{Summary}

Sterile agar beads plus Pseudomonas aeruginosa injected intratracheally produced local infection in rats, similar to that described for the injection of agar beads containing the same pathogen. It is suggested that it is not necessary for $P$. aeruginosa to be inside the beads to induce lung infection.

\section{Abbreviation}

cfu, colony forming unit

In 1979 , Cash and coworkers (2) described a rat model for chronic pulmonary Pseudomonas aeruginosa infection that consisted of intratracheal injection of agar beads containing the pathogen. Other investigators have used a similar system to produce models in guinea pigs (1) and cats (8). Different mechanisms have been proposed to explain enhanced Pseudomonas pathogenicity, not only in the Cash rat model, but also in human disorders like cystic fibrosis. There has been some speculation, for example, that coating of Pseudomonas by mucoid substances may provide survival advantages in the respiratory tract by protecting the microorganisms from phagocytic cells, antibodies and even antibiotics $(4,5,6)$. The importance of bacterial adherence to the epithelia, before replication and microcolony formation has also been recognized (7). In this report we present histopathologic and bacteriologic data obtained from rats in- jected intratracheally either with agar beads containing $P$. aeruginosa, agar beads mixed with $P$. aeruginosa or $P$. aeruginosa alone.

\section{MATERIALS AND METHODS}

Young adult outbred Wistar rats, $140-160 \mathrm{~g}$ in weight, were anesthetized with ether, and a small midline cervical incision was made to expose the trachea. Then, $0.20 \mathrm{ml}$ of the inoculum was injected intratracheally. One group was injected with agar beads containing $10^{5}$ cfu of $P$. aeruginosa; a second group received $10^{5} \mathrm{cfu}$ of $P$. aeruginosa; and the last group was injected with sterile agar beads plus $10^{5} \mathrm{cfu}$ of $P$. aeruginosa, mixed immediately before injection. $P$. aeruginosa ATCC 15152 was cultured overnight in $15 \mathrm{ml}$ tryptic soy broth at $37^{\circ} \mathrm{C}$; the pelleted cells were washed with cold saline, and resuspended in phosphate buffered saline, $\mathrm{pH}$ 7.2. Agar beads were prepared with or without $P$. aeruginosa as described previously (2). Groups of animals were sacrificed with a single dose of Nembutal (Abbott Laboratories, North Chicago, IL). The lungs were excised and the gross pathologic features recorded. The left lung was fixed by immersion in $10 \%$ buffered formalin and stained with hematoxylineosin. The right lung was homogenized in $5 \mathrm{ml}$ of cold distilled water in a Potter-Elvehjem homogenizer and appropriate dilutions of the homogenates plated for quantitation purposes in tryptic soy agar. Homogenate samples were also cultured in blood agar and eosin-methylene blue agar plates. Infecting flora were identified in each case by standard clinical laboratory procedures. 